\title{
Tubes or sheets: divergent aggregation pathways of an amphiphilic 2,7-substituted pyrene trimer
}

Cite this: Chem. Commun., 2015, 51, 16191

Received 22nd June 2015, Accepted 10th September 2015

DOI: $10.1039 / \mathrm{c} 5 \mathrm{cc} 05126 f$

www.rsc.org/chemcomm

\author{
Mykhailo Vybornyi, Yamileidi Bur-Cecilio Hechevarria, Marlene Glauser, \\ Alexander V. Rudnev and Robert Häner*
}

The self-assembly of an amphiphilic 2,7-linked pyrene trimer in an aqueous environment into two morphologically related forms is described. Supramolecular polymerization leads to the simultaneous formation of nanosheets and nanotubes.

The on-demand assembly of $\pi$-conjugated molecules in morphologically-defined patterns remains a desirable task. ${ }^{1-5}$ Inspired by the multifaceted and versatile properties of graphene, two-dimensional (2D) organic materials have attracted great interest, yet their preparation and handling remain a challenge. ${ }^{6-10}$ Tubular objects are morphologically related to 2D structures, such as ribbons or sheets, and can arise from the latter via appropriate connection of edges. Thus, the formation of supramolecular nanotubes via helical intermediates is a well-documented process. ${ }^{11,12}$ The description of shape-shifting pairs of covalent polymers is limited to the grapheneto-CNT transformation. ${ }^{13}$ Supramolecular self-assembly is a versatile tool for the preparation of morphologically adaptable platforms, ${ }^{14,15}$ primarily due to the non-covalent nature of the intermolecular interactions. ${ }^{16-19}$ We recently described the use of oligoarenotides, amphiphilic phosphodiester-linked arene oligomers ${ }^{20}$ for the "bottom-up" assembly of functional supramolecular polymers. ${ }^{21-23}$ The morphological features (nanosheets ${ }^{24,25}$ or fibers ${ }^{26}$ ) of the aggregates primarily depend on the substitution pattern of the aromatic units. The importance of pyrene and its derivatives as components of functional materials largely originates in the reliable control of the electronic properties via the aromatic substitution pattern as well as environmental influences. ${ }^{27-30}$ In comparison to other derivatives, 2,7-substituted pyrenes have for long been relatively little explored but recent synthetic advances ${ }^{31-34}$ triggered growing interest in these compounds. Thus, 2,7-substituted pyrenes were used for the preparation of solar cells, ${ }^{35}$ OLEDs, ${ }^{36}$ conjugated polymers, ${ }^{37,38}$ nanorings $s^{39,40}$ and covalent organic frameworks. ${ }^{41,42}$ Furthermore, they found applications as rotaxanes ${ }^{43}$ and tweezers ${ }^{44}$

Department of Chemistry and Biochemistry, University of Bern, Freiestrasse 3, CH-3012 Bern, Switzerland. E-mail: robert.haener@dcb.unibe.ch $\dagger$ Electronic supplementary information (ESI) available: Synthetic and analytical details, additional spectra and images. See DOI: 10.1039/c5cc05126f

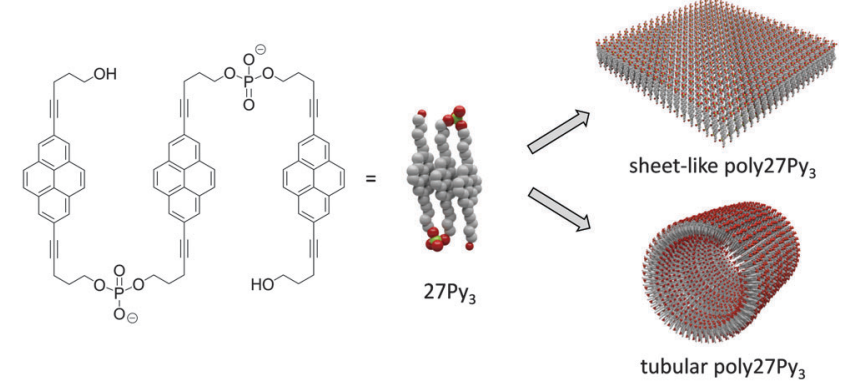

Scheme 1 Structure of $27 \mathrm{Py}_{3}$ and illustration of self-assembled sheetlike and tubular objects.

of single-walled carbon nanotubes as well as in hydrophobic host-guest nanocages. ${ }^{45}$ In this report, we demonstrate that an amphiphilic trimer of a 2,7-substituted pyrene $\left(\mathbf{2 7 P \mathbf { P } _ { 3 }}\right)$ selfassembles into 2D (sheet-like) and 1D (tubular) supramolecular polymers (poly27Py 3 , Scheme 1).

Oligomer $27 \mathbf{P y}_{3}$ was prepared via solid-phase synthesis. The required building block was synthesized as shown in Scheme 2 (see also ESI $\dagger$ ). Briefly, 2,7-dibromopyrene (1) was converted to the 2,7-dialkynyl-substituted derivative 2 via a Sonogashira

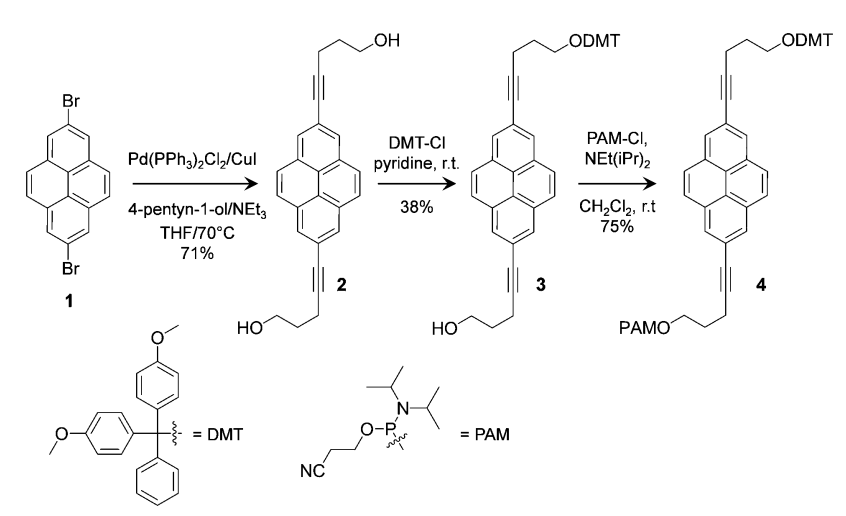

Scheme 2 Synthesis of phosphoramidite building block 4 . 


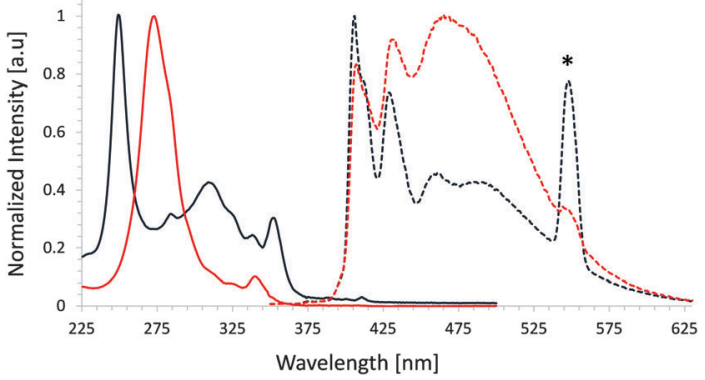

Fig. 1 Normalized UV/Vis (solid) and fluorescence (dashed) spectra of $27 \mathrm{Py}_{3}$ at $20{ }^{\circ} \mathrm{C}$ (black) and $80{ }^{\circ} \mathrm{C}$ (red). Conditions: $27 \mathrm{Py}_{3}=5 \mu \mathrm{M}$ in a mixture of aqueous buffer $(10 \mathrm{mM}$ sodium chloride, $10 \mathrm{mM}$ phosphate buffer, $\mathrm{pH}=7.2$ ) and ethanol $80 / 20 \mathrm{v} / \mathrm{v} ; \lambda_{\text {ex }}=275 \mathrm{~nm}$. * Second order transmission artefacts.

reaction. After DMT-protection, the obtained intermediate 3 was converted to phosphoramidite 4. All compounds were characterized by ${ }^{1} \mathrm{H},{ }^{13} \mathrm{C}$ NMR and HRMS. After synthesis on solid support, oligomer $27 \mathbf{P y}_{3}$ was purified by RP-HPLC and characterized by MS (see ESI $\dagger$ ).

The absorption and emission spectra of $\mathbf{2 7 P y _ { 3 }}$ were recorded in an aqueous mixture (aqueous buffer containing $20 \%$ ethanol, see Fig. 1). Temperature-dependent pyrene aggregation is accompanied by pronounced spectroscopic changes. At $80{ }^{\circ} \mathrm{C}$, the absorption spectrum consists of essentially two peaks, a very intense maximum at $273 \mathrm{~nm}$ and a weak maximum at $340 \mathrm{~nm}$. The shape

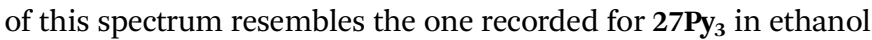
(see ESI $\dagger$ ). Under these conditions, $\mathbf{2 7 \mathbf { P y } _ { 3 }}$ exists as a molecularly dissolved trimer. The spectra are in-line with those reported for other 2,7-substituted pyrenes. ${ }^{29,46}$ Upon cooling of the aqueous solution from $80{ }^{\circ} \mathrm{C}$ to $20{ }^{\circ} \mathrm{C}$, the absorption spectrum experiences significant changes in both regions as a result of trimer aggregation ( $\rightarrow$ poly27Py $\mathbf{y}_{3}$ ). A new, blue-shifted band arises at $250 \mathrm{~nm}$ (Fig. 1). Furthermore, the appearance of several additional bands is observed, the most dominant ones being located at 309 and $352 \mathrm{~nm}$. These changes are ascribed to exciton coupling of assembled pyrenes. ${ }^{24,25,47}$

The fluorescence spectra of $27 \mathbf{P y}_{3}$ in an aqueous mixture consist of monomer and excimer emissions. ${ }^{27}$ The former covers the range of 380-500 nm and exhibits a well-defined vibronic structure (see also the spectrum of compound 2, ESI $\dagger$ ). For $27 \mathrm{Py}_{3}$ and its aggregates $\left(\mathbf{p o l y 2} 2 \mathbf{P y}_{3}\right)$ the broad and structure-less excimer band appears as an additional signal in the $400-625 \mathrm{~nm}$ region.

The aggregation-induced spectroscopic changes observed in aqueous solution were further substantiated by microscopic studies. AFM imaging of poly $27 \mathbf{P y}_{3}$ was performed on aminomodified mica plates. The images reveal two morphological types of supramolecular polymers, nanosheets and nanotubes (Fig. 2). The nanosheets appear as large-sized 2D objects with up to $200 \mu \mathrm{m}^{2}$ area and a uniform layer thickness of $2 \mathrm{~nm}$. This is consistent with a model of a hydrophobic array of stacked pyrenes sandwiched between two layers of negatively charged phosphates. The nanosheets exist predominantly as monolamellar objects, which is explained by Coulomb repulsion between individual sheets. Alternatively, poly27Py $\mathbf{P}_{3}$ exists in the form of
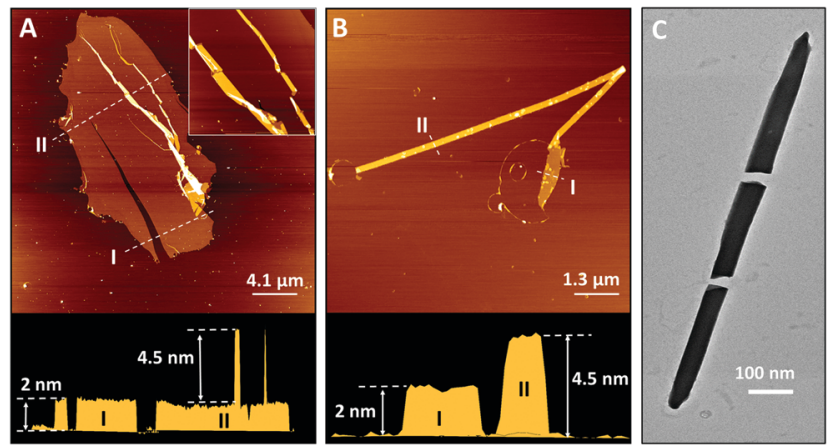

Fig. 2 Images of supramolecular polymers; AFM: (A) co-existing planar and tubular objects (inset: enlarged view of cross-sectional area II) and (B) nanotubes with small sheets attached; (C) TEM image. Samples were prepared via slow cooling $\left(0.1{ }^{\circ} \mathrm{C} \mathrm{min}^{-1}\right)$; conditions: see Fig. 1 .

nanotubes (Fig. 2). This morphology has rarely been observed with pyrene-containing aggregates. ${ }^{48}$ On a mica surface, the tubes appear as perfectly straight and flat bars with a thickness of $4.5 \mathrm{~nm}$ and a length of several micrometres. The bars exhibit a remarkably uniform width, which is in the range of 150$400 \mathrm{~nm}$ for individual objects (see also ESI $\dagger$ ). AFM data reveal a small but distinct difference in the thickness measured for collapsed tubes $(4.5 \mathrm{~nm})$ and two incidentally overlaid sheets (4.0 nm, see ESI $\dagger$ ). A thickness of $4.5 \mathrm{~nm}$ indicates a bilayer, which is formed by collapse of the nanotube during or after deposition and drying on the substrate surface. The increased thickness is most likely due to remnant salt, which is not removed in washing steps from the inner compartment of tubes. TEM images (Fig. 2 and ESI $\dagger$ ) confirm a tubular morphology. Tubes are characterized by a diameter in the range of $100-300 \mathrm{~nm}$ and a wall thickness of $\sim 2 \mathrm{~nm}$, as illustrated in Fig. 3. Some of the tubes exhibit sheet-like sections at their ends with a thickness of $2 \mathrm{~nm}$ (Fig. 2B, cross-section I). It is important to note that tubes are often associated with nanosheets (Fig. 2A). This may be an indication of divergent pathways leading to the parallel development of nanotubes and nanosheets at a certain stage of supramolecular polymerization. Formation of nanotubes is only observed upon slow cooling of the solution $\left(0.1^{\circ} \mathrm{C} \mathrm{min}{ }^{-1}\right)$, whereas fast cooling $\left(>10{ }^{\circ} \mathrm{C} \mathrm{min}^{-1}\right.$ ) only leads to nanosheets.

The self-assembly process was followed by temperaturedependent UV/Vis (Fig. 4) and fluorescence experiments (see ESI†). Slow cooling $\left(0.1^{\circ} \mathrm{C} \mathrm{min}{ }^{-1}\right)$ from $80^{\circ} \mathrm{C}$ to $20^{\circ} \mathrm{C}$ leads to a well-defined transition in both cases. Monitoring the absorption at $275 \mathrm{~nm}$ shows a transition starting at $65^{\circ} \mathrm{C}$. The process

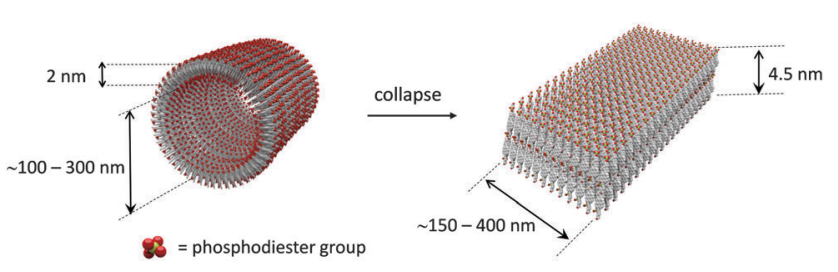

Fig. 3 Illustration of double layer formation by collapse of a nanotube on the surface. 


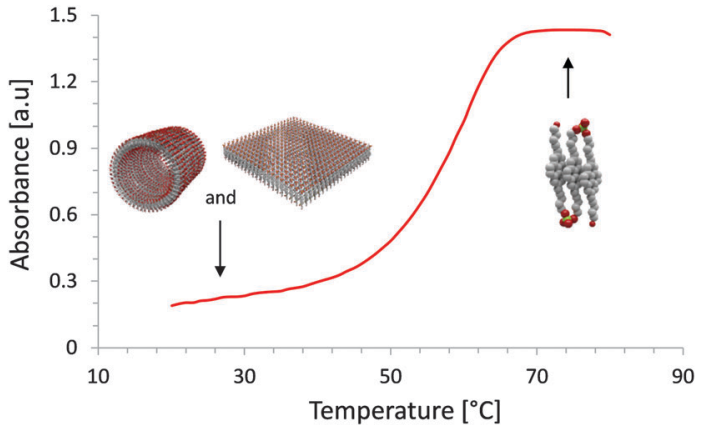

Fig. 4 Supramolecular polymer formation curve (cooling rate $0.1^{\circ} \mathrm{C} \mathrm{min}^{-1}$ ) recorded in aqueous medium (conditions as in Fig. 1) at $275 \mathrm{~nm}$.

can equally be followed by monitoring excimer emission at $480 \mathrm{~nm}$ (see ESI $\dagger$ ).

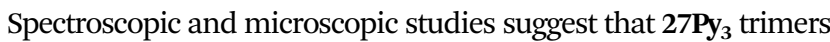
exist in the form of molecularly dissolved chains at elevated temperatures in aqueous solution. Upon slow cooling, the oligomers tend to aggregate due to strong $\pi$-stacking and hydrophobic interactions leading to the formation of supramolecular polymers (poly27Py $\mathbf{y}_{3}$ ), which consist of an inner pyrene layer sandwiched between densely-packed negatively-charged phosphates. The assembly process results in two morphologically related types of polymers, nanosheets and nanotubes. The structural flexibility of growing supramolecular 2D-polymers ${ }^{47}$ may lead to the sporadic formation of meta-stable, bowl-shaped or other non-planar conformations in the nucleation or early elongation stages. Bowl-shaped ends are observed in TEM images. These sites can serve as seeds for alternative morphologies from which the observed nanotubes develop as a result of competing assembly pathways.

In conclusion, we have described the self-assembly properties of an amphiphilic, 2,7-linked pyrene trimer $\left(\mathbf{2 7 P \mathbf { P } _ { 3 } )}\right.$ under aqueous conditions. Aggregation is accompanied by substantial spectroscopic changes. The supramolecular polymerization leads to the simultaneous formation of sheet-like and tubular objects. While the nanosheets exist as $2 \mathrm{~nm}$ thick monolayers, collapsed nanotubes are observed by AFM on the mica surface as highly regular, double-layered flat bars with a length of several micrometers. The findings are important for the design and development of functional supramolecular polymers.

This work was supported by the Swiss National Foundation (Grant 200020-149148).

\section{Notes and references}

1 Y. Yan and Y. S. Zhao, Chem. Soc. Rev., 2014, 43, 4325-4340.

2 S. I. Stupp and L. C. Palmer, Chem. Mater., 2014, 26, 507-518.

3 P. A. Korevaar, T. F. De Greef and E. Meijer, Chem. Mater., 2014, 26, 576-586.

4 A. Wilson, G. Gasparini and S. Matile, Chem. Soc. Rev., 2014, 43, 1948-1962.

5 S. Sengupta and F. Würthner, Acc. Chem. Res., 2013, 46, 2498-2512.

6 S. L. Cai, W. G. Zhang, R. N. Zuckermann, Z. T. Li, X. Zhao and Y. Liu, Adv. Mater., 2015, DOI: 10.1002/adma.201500124.

7 T. Govindaraju and M. B. Avinash, Nanoscale, 2012, 4, 6102-6117.

8 J. Sakamoto, J. van Heijst, O. Lukin and A. D. Schlüter, Angew. Chem., Int. Ed., 2009, 48, 1030-1069.

9 J. W. Colson and W. R. Dichtel, Nat. Chem., 2013, 5, 453-465.
10 M. E. Canas-Ventura, K. Ait-Mansour, P. Ruffieux, R. Rieger, K. Müllen, H. Brune and R. Fasel, ACS Nano, 2011, 5, 457-469.

11 T. G. Barclay, K. Constantopoulos and J. Matisons, Chem. Rev., 2014, 114, 10217-10291.

12 N. Kameta, H. Minamikawa and M. Masuda, Soft Matter, 2011, 7, 4539-4561.

13 H. E. Lim, Y. Miyata, R. Kitaura, Y. Nishimura, Y. Nishimoto, S. Irle, J. H. Warner, H. Kataura and H. Shinohara, Nat. Commun., 2013, 4, 2548.

14 N. Chandrasekhar and R. Chandrasekar, Angew. Chem., Int. Ed., 2012, 51, 3556-3561.

15 W. Li, Y. Kim and M. Lee, Nanoscale, 2013, 5, 7711-7723.

16 L. Yang, X. Tan, Z. Wang and X. Zhang, Chem. Rev., 2015, 115, 7196-7239.

17 M. Ramanathan, L. K. Shrestha, T. Mori, Q. Ji, J. P. Hill and K. Ariga, Phys. Chem. Chem. Phys., 2013, 15, 10580-10611.

18 D. Wang, G. Tong, R. Dong, Y. Zhou, J. Shen and X. Zhu, Chem. Commun., 2014, 50, 11994-12017.

19 A. Sorrenti, O. Illa and R. Ortuno, Chem. Soc. Rev., 2013, 42, 8200-8219.

20 R. Häner, F. Garo, D. Wenger and V. L. Malinovskii, J. Am. Chem. Soc., 2010, 132, 7466-7471.

21 V. L. Malinovskii, A. L. Nussbaumer and R. Häner, Angew. Chem., Int. Ed., 2012, 51, 4905-4908.

22 Y. Vyborna, M. Vybornyi, A. V. Rudnev and R. Häner, Angew. Chem., Int. Ed., 2015, 54, 7934-7938.

23 C. B. Winiger, S. Li, G. R. Kumar, S. M. Langenegger and R. Häner, Angew. Chem., Int. Ed., 2014, 53, 13609-13613.

24 M. Vybornyi, A. V. Rudnev, S. M. Langenegger, T. Wandlowski, G. Calzaferri and R. Häner, Angew. Chem., Int. Ed., 2013, 52, 11488-11493.

25 M. Vybornyi, A. Rudnev and R. Häner, Chem. Mater., 2015, 27, 1426-1431.

26 A. V. Rudnev, V. L. Malinovskii, A. L. Nussbaumer, A. Mishchenko, R. Häner and T. Wandlowski, Macromolecules, 2012, 45, 5986-5992.

27 F. M. Winnik, Chem. Rev., 1993, 93, 587-614.

28 T. M. Figueira-Duarte and K. Müllen, Chem. Rev., 2011, 111, 7260-7314.

29 A. G. Crawford, A. D. Dwyer, Z. Liu, A. Steffen, A. Beeby, L. O. Palsson, D. J. Tozer and T. B. Marder, J. Am. Chem. Soc., 2011, 133, 13349-13362.

30 H. Örücü and N. Acar, Comput. Theor. Chem., 2015, 1056, 11-18.

31 Y. Q. He and Y. W. Zhong, Chem. Commun., 2015, 51, 3411-3414.

32 S.-I. Kawano, M. Baumgarten, D. Chercka, V. Enkelmann and K. Müllen, Chem. Commun., 2013, 49, 5058-5060.

33 J. M. Casas-Solvas, J. D. Howgego and A. P. Davis, Org. Biomol. Chem., 2014, 12, 212-232.

34 A. G. Crawford, Z. Liu, I. A. Mkhalid, I. M. H. Thibault, N. Schwarz, G. Alcaraz, A. Steffen, J. C. Collings, A. S. Batsanov, J. A. Howard and T. B. Marder, Chem. - Eur. J., 2012, 18, 5022-5035.

35 S. S. Li, K. J. Jiang, C. C. Yu, J. H. Huang, L. M. Yang and Y. L. Song, New J. Chem., 2014, 38, 4404-4408.

36 D. Chercka, S. J. Yoo, M. Baumgarten, J. J. Kim and K. Müllen, J. Mater. Chem. C, 2014, 2, 9083-9086.

37 H. Chen, X. Hu and S. C. Ng, J. Polym. Sci., Part A: Polym. Chem., 2010, 48, 5562-5569.

38 S.-I. Kawano, C. Yang, M. Ribas, S. Baluschev, M. Baumgarten and K. Müllen, Macromolecules, 2008, 41, 7933-7937.

39 T. Iwamoto, E. Kayahara, N. Yasuda, T. Suzuki and S. Yamago, Angew. Chem., Int. Ed., 2014, 53, 6430-6434.

40 A. Yagi, G. Venkataramana, Y. Segawa and K. Itami, Chem. Commun., 2014, 50, 957-959.

41 Y. Zhou, Z. Wang, P. Yang, X. Zu and F. Gao, J. Mater. Chem., 2012, 22, 16964-16970.

42 S. Wan, J. Guo, J. Kim, H. Ihee and D. Jiang, Angew. Chem., Int. Ed., 2009, 48, 5439-5442.

43 A. Lopez-Moreno and E. M. Perez, Chem. Commun., 2015, 51, 5421-5424.

44 G. Liu, A. F. M. M. Rahman, S. Chaunchaiyakul, T. Kimura, Y. Kuwahara and N. Komatsu, Chem. - Eur. J., 2013, 19, 16221-16230.

45 T. K. Ronson, A. B. League, L. Gagliardi, C. J. Cramer and J. R. Nitschke, J. Am. Chem. Soc., 2014, 136, 15615-15624.

46 A. O. El-Ballouli, R. S. Khnayzer, J. C. Khalife, A. Fonari, K. M. Hallal, T. V. Timofeeva, D. Patra, F. N. Castellano, B. Wex and B. R. Kaafarani, J. Photochem. Photobiol., A, 2013, 272, 49-57.

47 N. Micali, M. Vybornyi, P. Mineo, O. Khorev, R. Häner and V. Villari, Chem. - Eur. J., 2015, 21, 9505-9513.

48 Y. Chen, B. Zhu, Y. Han and Z. Bo, J. Mater. Chem., 2012, 22, 4927-4931. 